\title{
Consumers' Reaction to Product Variety: Does Culture Matter?
}

\author{
Sayed Farrukh Ahmed \\ Senior Lecturer, School of Business, United International University \\ H-80, R-8/A, Satmasjid Rd, Dhanmondi, Dhaka-1209, Bangladesh \\ Tel: 880-19-1347-3223 E-mail: munna99185@yahoo.com
}

Md. Mohan Uddin (Corresponding author)

Assistant Professor, School of Business, United International University

H-80, R-8/A, Satmasjid Rd, Dhanmondi, Dhaka-1209, Bangladesh

Tel: 880-17-1308-1780 E-mail: mohanuddin@yahoo.com,mohanuddin@uiu.ac.bd

Mohammad Ahshanullah

Assistant Professor, School of Business, United International University

H-80, R-8/A, Satmasjid Rd, Dhanmondi, Dhaka-1209, Bangladesh

Tel: 880-18-1803-5494Ｅ-mail: sw72002@yahoo.com

\begin{abstract}
Substantial cultural variations should be considered in establishing marketing strategies around the world. This paper stresses several aspects. Initially, consumers' perceptions of variety differ from the actual variety provided by a manufacturer or retailer. Literature indicates that consumers' benefits and costs of perceived variety differ systematically across cultures. Current cultural theory suggests that they also encounter greater cognitive and emotional costs than individuals in collectivistic cultures when ultimately choosing. The objective of this paper is to point out specific implications. First, theories on variety perception have been discussed in order to highlight consumers' benefits and costs of variety. Second, an attempt is made to find out whether culture-oriented market has facilitated the successful acceptance of product by the consumers around the world or not.
\end{abstract}

Keywords: Product variety, Cultural variation, Marketing strategy, Consumer reaction

\section{Introduction}

The question of standardization or adaptation is one of the core issues in international marketing. Multidomestic strategies have been compared to adaptive strategies with regard to the overall marketing mix (Zoe and Tamer 2002). In fact, advertising has received the most attention (Sirisagul 2000). Although some researchers claim that markets are homogenous and firms should consequently apply similar strategies across countries (Levitt 1983), the prevailing view seems to contradict this notion. Given the fierce competition in the domestic market, combined with increasing opportunities in many overseas markets, more and more local companies are going international. However, when the cultural backgrounds of each overseas market are substantially different, the acceptance of the product in the overseas market is highly challenged. Most researchers agree that cultural differences lead to different consumer responses across countries. Evidence indicates that cultures differ with regard to brand perceptions (Aker 2001), perceptions of risk and brand loyalty (Lehmann 1998), as well as effective advertising (Biswas 1992). Consequently, a certain degree of adaptation of marketing strategies is necessary for optimal overall value creation.

\section{Objective of the study}

The objective of this study is to find out whether cultural differences have significant impact on consumers' respond to product variation or not. From a managerial perspective, many companies are discovering that success depends on utilizing opportunities to meet the demands of customers. Marketers, in order to more effectively reach their target markets, must have an understanding of how intra-national cultures impact product-specific purchases by consumers.

\section{Literature Review}

Over the last several years, the body of literature that explores the complex relationship between culture and the acceptance of different products has grown exponentially. One of the lessons learned from studying social psychology is that cultural variations have significant impact on the way people view the world and that these views ultimately affect 
their response to various products (Levav and Ariely 2000). Seemingly, there is agreement in the marketing literature that culture greatly influences the way consumers perceive and behave (Bettman, James and Park 2000). Huffman and Kahn (2000) show that the process of having both the marketer and consumer involved in learning about the consumer's preference can lead to higher satisfaction. The authors suggest that customers should be engaged in the process of formulating preferences on each of a product's attributes. That is, customers should first learn about the attributes and then determine their preference.

Overall, product variety has been of increasing interest to marketing researchers. Indeed, considerable effort has been invested in studying consumers' reactions to variety and optimal strategies for providing variety (Levav and Ariely 2000). The importance of variety lies in the fact that industries are becoming increasingly competitive. Deregulated, globalization and information easily accessible by consumers result in a growing need to meet consumers' preferences as closely as possible and equally important develop a long-term relationship with customers (Kahn 1998).

The increasing trend toward globalization of business activities provides a strong reason for understanding the cultural context of consumer behaviors (Gilovich and Medvec 2001). This trend has heightened the importance of understanding national cultural influences on the consumers' innovativeness and the diffusion of innovations. But this subject has been examined only to a limited extent.

The international marketing literature contains numerous studies concerning behavioral differences in consumers across cultures and nations (e.g. Kahn and Lehmann 2001); Huber 2000). Although these researches have made significant contributions toward understanding differences between nations, there appears to be a gap in the literature about sub-cultural differences within national boundaries, or intra-national differences (Anderson 2003). Concurrently, marketing practitioners have stressed that understanding culture is very important when attempting to market to new areas (Agarwal 2001). Despite the increased importance of cultural-related research in marketing, only a limited amount of attention has been given to ethnic sub-cultures (Gilovich, Wang and Regan 2003). An understanding of cultural differences is essential for greater success in comprehending and capitalizing on differences that exist within a nation.

However, there are intriguing findings such as those of Iyengar and Lepper (2003) which show that excessive choice can actually result in reduced instead of increased sales. To provide a sense of proportion, Drolet (2002) reports that when Procter \& Gamble reduced the number of versions of their 'Head \& Shoulders' shampoo from 26 to 15 they experienced an increase in sales of 10 percent. Considering the additional costs that arise from the complexity of manufacturing and marketing a variety of 26 products, it becomes quite clear that variety has substantial effects on a firm's performance.

\section{Consumers' perceptions of variety}

Sometime, it may happen that actual variety need not necessarily be equal to the variety perceived by consumers. For example, a car dealer may provide a wide range of automobiles with respect to vehicle style, engine type or color. Individual customers, on the other hand, may only be interested in a subset of vehicles, e.g. black, blue or silver station wagons with diesel engines. Alternatively, Chinese restaurants frequently offer a limited selection of various ingredients. When all possible combinations are listed, the variation among options seems greater than the actual variety. Obviously, the mere number of options represents a type of variety that is not ignored by consumers. A supermarket offering 15 different flavors of jam will offer customers more flexibility in terms of taste than a supermarket offering a limited selection of 6 flavors. However, consumers' perceptions are often exploited by contextual factors. For example, customers perceive that physically bigger shelf spaces have provided more variety than smaller ones even in cases when the actual number of distinct items is the same.

In addition, perceived variety is determined by the distinctiveness of options and the preferences of the consumers (Kahn and Lehmann 2001). For example, the introduction of a new computer monitor with a drastically increased screen size may extend the possible uses of the product (e.g. towards effective picture editing). An even larger increase in perceived variety results from alternatives that include new product attributes such as flat screen monitors that can be easily rotated to make different working tasks more efficient.

Furthermore, companies can actively increase perceived variety without having to produce entirely new product. Gilovich, Wang and Regan (2003) differentiate between adaptive and cosmetic customization. Examples of adaptive customization include office chairs that can be adapted to different physical characteristics of customers. Chinese restaurants also allow for a kind of adaptive customization by enabling customers to spice their meals according to their individual preferences. Cosmetically customized products allow for variation not with regard to the actual product usage but with regard to its appeal and look (Kahn 1998). Car manufacturers such as Volkswagen or Daimler Chrysler aim to offer customers additional benefits by providing limitless possibilities with regard to interior and exterior customization as they provide their cars in effectively any color customers wish to order.

\section{Consumers' benefits of perceived variety}

There are two distinct motives for consumers' respond to variety. First of all, there is the issue of constrained choice. 
Behavioral decision theory views preferences as at least partially constructed in the light of the available options (Bettman, James and Park 2000). In most cases, consumers do not possess a clear set of preferences to make a purchase decision when approaching different options. These are about to be constructed when individuals start processing the information on individual options. Consequently, at the decision stage consumers are faced with a significant amount of uncertainty about which option best matches their future preferences. In the light of uncertainty about future preferences, consumers aim to maintain flexibility and consequently choose larger assortments.

Decision makers may realize that their chances of making an optimal choice are better when choosing between a larger numbers of options (Levav and Ariely 2000). With respect to the initial evaluation of choice, Iyengar and Lepper (2003) found significant cultural differences. The authors compared Japanese and American students on their desire for having choice. When both groups of students were asked to list occasions where they wished not to have a selection of alternatives available, 30 per cent of the American students replied, they always wished to have a choice. None of the Japanese students replied alike. Similarly, in their review of cultural psychological studies, Kim and Drolet (2003) conclude that not all participants are equally stimulated by choice opportunities. It seems that in collectivistic cultures such as the Japanese, smaller assortments may not be rejected as often as in individualistic cultures such as the one of the United States of America.

An important consumer benefit of variety is the ability to seek a diversity of options over time, i.e. variety seeking. Many consumer goods are bought in high frequency, consumers are familiar with the options being offered, and purchases are of relatively low risk. Under such circumstances, the ability to diversify consumption may be of particular value to consumers (Kahn 1998). Derived variety seeking occurs because shoppers may have multiple needs to satisfy, use products for multiple occasions or even buy products for multiple consumers. Direct variety seeking, on the other hand, occurs because of an internal desire for change or stimulation by novelty.

Derived variety seeking can be attributed to external constraints. If consumers find no product that satisfies all of their needs, consumers may naturally have to purchase multiple items. There is no reason to believe that such external reasons for variety seeking may vary systematically across cultures. However, this is not the case for direct variety seeking. Here, different consumer behavior across cultures is highly likely. The research of Levav andAriely (2000) has shown that interpersonal choice contexts lead Americans to make different choices than other individuals because this enables them to portray an image of uniqueness to their social environment. In the American culture, an image of imitation is perceived as a threat rather than an opportunity.

The link between behavioral change and uniqueness is not limited to variety seeking in group settings. For example, Drolet (2002) found that individuals who score high on a need for uniqueness scale seek to apply different choice strategies across a sequence of decisions. The author concludes that this happens because of consumer's desire for counter formality. While such a desire represents Western cultural systems very well, it does not fit with the cultural norms of many Asian countries. While in the American cultural context, individuals are encouraged to follow their own feelings, in many Asian countries being different has mainly negative associations (Kim and Drolet 2003).

Based on the identified cultural differences one might simply conclude that high variety assortments should be offered in individualistic cultures, whereas in collectivistic cultures competition would not be expected to focus on variety and, therefore, firms may offer fewer items.

\section{Consumers' costs of perceived variety}

Until the point where consumers need to compare individual alternatives and deliberate about which option to select, there are little costs associated with variety. Up to the product selection stage of the purchase decision variety will serve to attract consumers, especially those in Western cultures. However, when consumers need to evaluate each of the available alternatives and furthermore turn down options in order to make a purchase, variety brings about emotional and cognitive costs for the decision maker. However, decision tasks with a higher perceived variety include a larger number of acceptable options. It is operationalised by decomposing choice strategies into sets of components, such as reading information, comparing alternatives on attributes or computational tasks such as calculating the size of a difference (Agarwal 2001)).The effort of thinking depends both on the complexity of the task applied by the decision maker. At the very least, a larger number of acceptable options require a larger number of information accesses and comparison activities. If decision makers apply a more accurate decision making strategy and weight individual product attributes by their subjective importance, the effort increases further due to computational activities such as multiplications and subtractions. Consequently, perceived variety does not influence the cognitive effort of each consumer in the same way. The effect rather depends on the type of decision making strategy typically applied (Hofstede 2001).

It can be said that variety increases the responsibility of the decision maker for the outcome he selects. In an extreme case, where consumers only have one option to choose from, e.g. a regulated telephone monopoly, individuals may be dissatisfied with the service they receive but they are not responsible for their dissatisfaction. On the other hand, when 
multiple service providers are available to choose from, the individuals themselves are responsible for paying higher fees or receiving inferior services as compared to other consumers.

However, there are several strong reasons that suggest that counterfactual thinking and feelings of regret are not independent of culture. Firstly, it is important to note that regret does not depend on satisfaction. Levitt (1983) has shown that regret can occur independent of whether or not an individual is satisfied with a selected outcome. To illustrate this, think about a consumer who has decided between two summer holiday destinations. Even though the location he finally chooses may have good weather, a nice hotel room and so forth, he may still question whether or not the competing destination would not have been a better choice. As such regret is always related to decision making. One of its sources for discomfort is the threat to an individual's self-conception as an able decision maker.

Iyengar and Lepper (2003) specifically concentrate on cultural differences with regard to post-decisional regret. The author asked participants from Japan, Russia, China and the United States to describe what they regretted most when looking back at their lives. Intercultural comparisons display no significant difference with regard to the tendency to regret inaction more than action over a long time period. However, it must be noted that Gilovich, Wang and Regan (2003) have shown that regret operates differently whether individuals look back at a recent choice or at a lifetime of decisions.

\section{Findings of the study}

Sometimes, consumers have taken their buying decision based on feelings and emotions. Also, sometimes, it happens that consumers like something but don't really know why, they just do. Many people enjoy running and many people enjoy marathons, but most would find it hard to explain why. Globalization is changing the way consumer goods companies conduct business. Many companies have found that globalization often offers significant economies of scale; producing, distributing, and promoting new products in multi-cultural markets, or even globally, can cost substantially less per customer than catering to individual culture.

Suppose that a consumer product company had enjoyed great success in Bangladesh with Product X. It decided to introduce Product $\mathrm{X}$ in several neighboring countries as well. Assuming that consumer acceptance of the product would be equally strong abroad, the company made plans to increase production and distribute Product $\mathrm{X}$ in local retail outlets. Six months after the launch in the new markets, combined sales were well under the projected goal. The product quickly lost the support of retailers and was pulled from the shelves. What went wrong? The answer may be that the culture of neighboring countries may not support the product. Consumers may not be satisfied with the product attributes. This failure may show that launching new products globally raises many new questions and issues. The product must meet a consumer need or provide a consumer benefit. But it is not easy for consumer package goods (CPG) companies to interpret the responses of consumers living in different cultures and countries around the globe. The business should evaluate its potential profitability before committing to the investment required for a full- scale market launch.

Of course, large companies operating in a single nation or even a single city don't standardize everything they make, sell, or do. They have product lines instead of a single product version, and multiple distribution channels. There are neighborhoods, local, regional, ethnic and institutional differences, even within metropolitan areas. But although companies customize products for particular market segments, they know that success in a world with homogenized demand requires a search for sales opportunities in similar segments across the globe in order to achieve the economies of scale necessary to compete.

Every year businesses spend millions of dollars researching, developing, and launching new products and services to consumers all over the world. Firms that maintain a higher-than-average revenue growth typically are engaged in continuous introduction of new products and/or operating and expanding internationally. The costly nature of research and development as well as the expense associated with launching new products result in a need for companies to better understand the cultural variations.

In particular, a person in one cultural context might make a choice in order to express individuality and appear unique. In this cultural context, choice is self-expression and a person can demonstrate his or her own unique blend of volition, feelings, and opinions through the act of choice. In this context, you are what you choose, and you can show who you are by what you choose: the hairstyle you choose to wear, the car you choose to drive, the person you choose to marry, and the presidential candidate for whom you choose to vote.

It can be said that a culture-oriented market leads to superior performance, at least in part, because of the new products that are developed and are brought to market. Also, a culture-oriented market enhances organizational innovativeness and new product success, both of which in turn improve organizational performance. Through the new product development activities, a culture-oriented market is converted into superior performance. One of the advantages of modern economy is that the marketplace can provide the consumer with an adequate choice of goods and services as well as the likelihood of satisfaction with that choice. In an ideal world, every product and service would be delivered flawless. However, sometimes products and services turn out not to be so perfect, necessitating the promotion of 
consumers' rights to develop a consumer-oriented product.

\section{Managerial implications}

As cultural variations increase in size, marketers must develop knowledge of consumer characteristics and group-level preferences to more effectively deploy resources (both human and capital) to meet and exceed the growing needs of these markets. Different consumer needs and responses require different marketing tactics and in some circumstances, different marketing strategies altogether.

International marketers should be cautious about understanding cultural differences when developing marketing activities. Cultural differences in actual advertisements and their prompted reactions should be extensively examined. It can be said that offering a broad product line should be conducive to superior market share performance. At the same time, today's multinational companies are equipped with management techniques and technologies such as flexible manufacturing, the use of standardized components, as well as flexible supply chain management. The cost efficient production capacities for manufacturing a wide variety of items, and the demand for meeting the individual taste of each consumer has led many firms to provide excessive choice. As a result, regular supermarkets carry entire isles of cereals, potato chips or soft drinks.

\section{Conclusion}

With this paper we have intended to point out that substantial cultural differences are to be expected when variety is provided to consumers around the world. This is important, since the provision of variety is a key marketing instrument. Offering a high variety can extend visibility, drive competitors out of the market, enable companies to better understand the preferences of their customers, make use of economies of scope or simply capitalize on previous brand investments. Obviously, determining the right amount of variety to provide is no easy task even in single markets such as the United States. Since variety exerts a direct and immediate impact on sales, providing the right amount of choice in regional markets is a key challenge in international marketing.

Today, research on cross cultural differences regarding consumer reactions to variety is scarce. We have raised some important issues that deserve further attention. The first topic regards cultural differences in reaction to variety at the early stages of the purchase decision process where consumers have yet to decide for a single alternative. Obviously, having multiple options will be valuable in any cultural background.

It would be of great interest to replicate existing studies in Asian cultures that have been previously conducted in Western cultures. For example, it is most likely that variety seeking in group settings will substantially differ across cultures. Additionally, it is quite reasonable to assume that simultaneous and sequential decisions will yield little differences with regard to variety seeking in collectivistic cultures.

In our view, as we have outlined for the area of variety, research that tests cultural differences has a substantial potential to enhance our knowledge in the field of international marketing.

\section{References}

Aaker, J. (2001). Consumption symbols as carriers of culture: a study of Japanese and Spanish brand personality constructs. Journal of Personality and Social Psychology, 81 (March), 492-508.

Agarwal, K. (2001). Review of 40-year debate in international advertising. International Marketing Review, 12 (January), 26-48.

Anderson, C. (2003). The psychology of doing nothing: forms of decision avoidance result from reason and emotion. Psychological Bulletin, 129 (February), 139-167.

Bettman, James R. \& Park, W. (2000). Effects of prior knowledge and experience and phase of the choice process on consumer decision processes: a protocol analysis. Journal of Consumer Research, 7 (June), 234-248.

Biswas, A. (1992). A comparison of print advertisements from the United States and France. Journal of Advertising, 21 (April), 73-81.

Drolet, A. (2002). Inherent rule variability in consumer choice: changing rules for change's sake. Journal of Consumer Research, 29(March), 293-305.

Gilovich, T. \& Medvec, V. (2001). The experience of regret: what, when and why. Psychological Review, 102(February), 379-395.

Gilovich, T. Wang, R., \& Regan, D. (2003). Regrets of action and inaction across cultures. Journal of Cross-Cultural Psychology, 34 (July), 61-71.

Hofstede, G. (2001). Culture's Consequences: Comparing Values, Behaviors, Institutions, and Organizations across Nations. Sage, Thousand Oaks, CA.

Huber, O. (2000). The influence of some task variables on cognitive operations in an informations-processing decision 
model. Acta Psychologica, 45 (April), 187-196.

Huffman, C. \& Kahn, B. (2000). Variety for sale: mass customization or mass confusion? Journal of Retailing, 74 (April), 491-513.

Iyengar, Simon S. \& Lepper, M. (2003). Rethinking the value of choice: a cultural perspective on intrinsic motivation. Journal of Personality and Social Psychology, 76 (March), 349-366.

Kahn, B. (1998). Dynamic relationships with customers: high variety strategies. Journal of the Academy of Marketing Science, 26 (January), 45-53.

Kahn, B. \& Lehmann, D. (2001). Modeling choice among assortments. Journal of Retailing, 67 (March), 274-289.

Kim, H. \& Drolet, A. (2003). Choice and self-expression: a cultural analysis of variety-seeking. Journal of Social Psychology, 85 (February), 373-382.

Lehmann, R. (1998). Customer reactions to variety: too much of a good thing? Journal of the Academy of Marketing Science, 26 (January), 62-65.

Levav, J. \& Ariely, D. (2000). Sequential variety-seeking in group settings: taking the road less traveled and less enjoyed. Journal of Consumer Research, 27 (March), 279-290.

Levitt, T. (1983). The globalization of markets. Harvard Business Review, 61(March), 92-102.

Sirisagul, K. (2000). Global advertising practices: a comparative study. Journal of Global Marketing, 14 (March), 77-97.

Zou, S. \& Tamer, S. (2002). The GMS: a broad conceptualization of global marketing strategy and its effect on firm performance. Journal of Marketing, 66(April), 40-56. 